\title{
Screening of Multi-trait PGPR from Rhizosphere of Sugarcane (Saccharum officinarum L.)
}

\author{
Hiral Bhanderi and M.D. Khunt ${ }^{*}$ \\ Department of Plant Pathology, N. M. College of Agriculture, Navsari Agricultural \\ University, Navsari-396450, India \\ *Corresponding author
}

\section{A B S T R A C T}

\section{Keywords}

Nutrient

availability, Plant growth promotion, PGPR, IAA production, ACC deaminase

Article Info

Accepted:

07 May 2019

Available Online:

10 June 2019

\begin{abstract}
Plant Growth Promoting Rhizobacteria (PGPR) are a group of rhizospheric bacteria, found in association with plant roots and enhance the growth of plant directly or indirectly. To isolate multi-trait PGPR, total 7 soil sample were collected from sugarcane rhizosphere with diverse previous cropping pattern. Total 38 distinct isolates were obtained in pure culture from above collected samples, were screened for their ability of plant growth promoting characters in in vitro conditions. Out of this, $100 \%$ showed antagonistic potential, $55.26 \%, 42.11 \%$ and $52.63 \%$ were positive for protease, amylase and lipase secretion respectively. In terms of increase in nutrient availability, $18.42 \%, 39.47 \%$, $26.32 \%$ and $31.58 \%$ were showing positive phosphate solubilization, potash mobilization, zinc solubilization and nitrogen fixation respectively. Indole-3-acetic acid production was detected in $31.58 \%$ isolates. Least per cent of isolates i.e. $13.16 \%$ were found positive for ACC deaminase activity. Two multi-trait and most potent PGPR isolates were screened and identified as Myroids profundi and Proteus mirabilis on the basis of 16s r-RNA sequencing method.
\end{abstract}

\section{Introduction}

Sugarcane (Saccharum officinarum L.) is a long duration, perennial grass belonging to family Poaceae. It is a $\mathrm{C}_{4}$ plant, generally grown in tropical and sub-tropical regions worldwide for mainly sugar and jeggery production. Plant Growth Promoting Rhizobacteria are a group of naturally occurring beneficial soil bacteria, mainly present in the rhizosphere region of plant and have the capability to stimulate plant growth. The term Plant Growth Promoting
Rhizobacteria (PGPR) was first used by Kloepper and Schroth (1978) to denote plant beneficial rhizospheric bacteria. Rhizosphere posses highly diversified microbial community with great level of microbial activity, particularly because of nutrients secreted by plant root in the form of soluble exudates such as amino acids, organic acids and other photosynthates (Nihorimbere et al., 2011).

Rhizospheric bacteria promote plant growth by direct and indirect mechanisms. Direct 
mechanisms include increase availability of nutrients for plant absorption, phytohormone production, etc. (Glick, 1995). Indirect mechanisms of plant growth promotion include biological control of plant pathogen, increase tolerance of plant to stresses, etc. (Glick, 1995).

Use of agrochemicals in agriculture poses a serious threat on soil health, harmful for soil flora and fauna (Yu et al., 2009). However, use of PGPR is eco-friendly in the enhancement of plant health and to promote plant growth (Calvo et al., 2014). Mainly PGPR genera characterized are Azotobacter, Azospirillim, Bacills, Enterobacter, Klebsiella, Serratia, etc. (Glick, 2012)

\section{Materials and Methods}

\section{Collection of soil samples and isolation of PGPR}

Total seven (OF, CFP, SWM, CAF, MSR-E, MSR-N and CFA) soil samples were collected from rhizosphere region of sugarcane from Navsari Agricultural University, Navsari campus by considering diverse past cropping pattern.

Isolation of PGPR from collected soil samples was performed as per procedure given by Chakraborty et al., (2011) with slight modification. Briefly, $1 \mathrm{~g}$ soil was mixed with $25 \mathrm{ml}$ of sterile distilled water followed by serial dilution and suspension was inoculated on nutrient agar (NA) plates. Well isolated colonies, with distinct morphology were isolated into pure culture form.

\section{Screening of bacteria}

Isolates were screened for plant growth promoting characters in in vitro conditions. Following methodologies were adapted for screening of PGPR for different parameters.

\section{ACC deaminase activity}

ACC deaminase producer microbes were screened as per procedure given by Rajnish and Prabhat (2015) on DF (Dworkin and Foster) minimal medium containing ACC (3.0 $\mathrm{mM}$ ) as sole source of nitrogen. Minimal medium without ACC were kept as negative control and with $0.2 \%\left(\mathrm{NH}_{4}\right)_{2} \mathrm{SO}_{4}$ as positive control.

\section{Phosphate solubilization}

Rate of phosphate solubilization was checked by inoculating bacteria on Pikovskya's medium followed by measurement of zone index (Pikovskaya, 1948).

\section{IAA production}

IAA estimation was done by method given by Dobbelaere et al., (1999) in the medium amended with L-tryptophan.

\section{Antagonistic test}

Biocontrol ability of the isolates was evaluated against Sclerotium rolfsii by dual culture method. Efficiency of isolates was judged on per cent growth inhibition (PGI) method given by Vincent (1947).

\section{Nitrogen fixation}

Nitrogen fixation ability of isolates was judged by inoculating pure culture on nitrogen free Ashby's Mannitol Agar medium. Presence of growth after $48 \mathrm{hrs}$ of incubation at $28^{\circ} \mathrm{C}$ was taken as positive test for nitrogen fixation.

\section{Potash mobilization}

Rate of potash mobilization was checked by incubating bacteria on medium containing glucose yeast extract calcium carbonate (GYC) medium. 


\section{Zinc solubilization}

Zinc solubilization was determined on mineral salt agar medium amended with $1 \%$ $\mathrm{ZnO}$ (zinc oxide) substrate. The actively growing cultures were spot inoculated on the medium, incubated at $28^{\circ} \mathrm{C}$ followed by measurement of solubilization (Venkatakrishnan et al., 2003).

\section{Extracellular enzymes production}

Extracellular enzymes proteases, lipases and amylases were detected in the medium with specific substrates i.e. casein, tributyrene and starch, respectively. Zone of clearance near colony was taken as an evidence of positive test.

\section{Identification of isolates}

Potent PGPR isolates were identified by 16'S r-RNA sequencing method.

\section{Results and Discussion}

\section{Isolation and in vitro screening}

Plant require several nutrients in large amount, termed as macronutrients as they are the building blocks of plant biomolecules and many of them in small amount (Micronutrients), as they are important as a cofactor of enzymes (Morgan and Connolly, 2013).

Plant continuously absorb nutrient from soil and produce nutrient deficiency symptoms on leaves like chlorosis, necrosis, distorted edges, size reduction of leaf, etc. (Jayalakshmi and Radha, 2017). Nutrient deficiency can be overcome by applying chemical fertilizers; however, it is expensive and environmental polluting too. Many PGPR can make nutrient available for metabolism and by eco-friendly manner.
Out of total seven soil samples (OF, CFP, SWM, CAF, MSR-E, MSR-N and CFA), altogether 38 PGPR isolates were obtained in pure culture form. All the isolates were screened for their efficacy of plant growth promoting characters such as nitrogen fixation, phosphate solubilization, zinc solubilization, potash mobilization, ACC deaminase activity, IAA production, antagonistic potential, extracellular enzyme production, etc.

Experimental data pertaining to multiple plant growth promoting potential of isolates is represented in table 1. Overall, in terms of increase of nutrient availability, 7 isolates $(18.42 \%)$ were positive for phosphate solubilization, 15 (39.47\%), $10(26.32 \%)$ and $12(31.58 \%)$ were found positive for potash mobilization, zinc solubilization and nitrogen fixation respectively. ACC deaminase activity is important for plant tolerance against abiotic stresses by degrading immediate precursor of ethylene (Glick et al., 1994). Out of all the isolates, only 5 isolates (13.16\%) were ACC deaminase positive.

Indole 3-acetic acid is a plant growth promoting hormone, a common product of Ltryptophan metabolism produced by many root inhabiting bacteria (Lynch, 1985). Among all the isolates screened, 12 isolates $(31.58 \%)$ were positive for IAA in in vitro conditions, in the range of 7.2 to $55.9 \mu \mathrm{g} / \mathrm{ml}$. Additionally, 21 (55.26\%), $16(42.11 \%)$ and $20(52.63 \%)$ were positive for extracellular hydrolytic enzymes protease, amylase and lipase secretion respectively.

Many PGPR have also capacity to control plant pathogens by antagonism by siderophore production, antibiotic secretion and other mechanisms like induced systemic resistance (ISR) and systemic acquired resistance (SAR) in the plant (Beneduzi et al., 2012). 
Int.J.Curr.Microbiol.App.Sci (2019) 8(6): 617-623

Table.1 In vitro screening of different isolates

\begin{tabular}{|c|c|c|c|c|c|c|c|c|c|c|c|}
\hline $\begin{array}{l}\text { Soil sample } \\
\text { No. }\end{array}$ & Isolate no. & \begin{tabular}{|c|}
$\mathbf{P}$ \\
Solubilization*
\end{tabular} & \begin{tabular}{|c|}
$\mathbf{K}$ \\
mobilization*
\end{tabular} & \begin{tabular}{|c|} 
Zinc \\
solubilization*
\end{tabular} & $\mathbf{N}_{2}$ fixation & $\begin{array}{l}\text { ACC deaminase } \\
\text { activity }\end{array}$ & $\begin{array}{c}\text { IAA production } \\
(\mu \mathrm{g} / \mathrm{m})\end{array}$ & $\begin{array}{c}\text { Protein } \\
\text { degradation }\end{array}$ & $\begin{array}{c}\text { Starch } \\
\text { degradation }\end{array}$ & $\begin{array}{c}\text { Lipid } \\
\text { degradation }\end{array}$ & $\begin{array}{c}\text { Antagonistic } \\
\text { potential }\end{array}$ \\
\hline \multirow[t]{7}{*}{ OF } & OF-1 & - & 2.35 & 2.91 & - & + & - & + & + & + & $07.05 \%$ \\
\hline & OF-2 & - & - & - & - & - & - & - & - & - & $03.52 \%$ \\
\hline & OF-3 & - & - & - & - & - & - & - & + & + & $85.88 \%$ \\
\hline & OF-4 & 5.45 & 2.35 & 3.42 & - & + & 30.5 & + & + & + & $62.35 \%$ \\
\hline & OF-5 & - & 1.95 & 2.11 & + & - & 7.2 & + & + & + & $21.17 \%$ \\
\hline & OF-6 & - & - & - & + & - & 48.2 & & - & + & $52.94 \%$ \\
\hline & OF-7 & - & - & - & - & - & - & + & - & - & $76.47 \%$ \\
\hline \multirow[t]{2}{*}{ CFP } & CFP-1 & - & 2.35 & - & + & - & - & + & + & - & $24.70 \%$ \\
\hline & CFP-2 & - & - & - & - & - & - & + & - & - & $72.94 \%$ \\
\hline \multirow[t]{9}{*}{ SWM } & SWM-1 & - & - & - & - & - & - & + & - & - & $72.94 \%$ \\
\hline & SWM-2 & - & - & - & - & - & - & + & - & + & $35.29 \%$ \\
\hline & SWM-3 & - & 4.21 & - & - & - & - & + & + & + & $17.64 \%$ \\
\hline & SWM-4 & 4.89 & 3.22 & 2.98 & - & - & 55.9 & + & - & + & $64.70 \%$ \\
\hline & SWM-5 & - & - & - & + & - & - & - & - & + & $23.52 \%$ \\
\hline & SWM-6 & 3.22 & 2.85 & 3.25 & + & - & 33.2 & - & + & - & $68.23 \%$ \\
\hline & SWM-7 & - & - & - & - & - & - & + & - & - & $17.64 \%$ \\
\hline & SWM-8 & - & 2.15 & - & + & - & 39.2 & + & - & - & $50.58 \%$ \\
\hline & SWM-9 & - & 1.98 & - & + & - & 47.4 & - & - & + & $62.35 \%$ \\
\hline \multirow[t]{8}{*}{ CAF } & CAF-1 & - & 4.31 & - & - & + & 12.3 & - & - & - & $48.23 \%$ \\
\hline & CAF-2 & - & 3.22 & - & - & - & - & + & & + & $15.29 \%$ \\
\hline & CAF-3 & - & - & - & - & - & - & + & + & + & $80.00 \%$ \\
\hline & CAF-4 & - & - & - & - & - & - & & + & - & $15.29 \%$ \\
\hline & CAF-5 & - & 2.11 & - & + & - & 9.5 & + & - & + & $18.82 \%$ \\
\hline & CAF-6 & 1.43 & 1.87 & 3.55 & + & - & - & - & + & - & $50.58 \%$ \\
\hline & CAF-7 & - & - & - & - & - & 44.5 & - & - & - & $07.05 \%$ \\
\hline & CAF-8 & - & 3.11 & - & - & - & 32.1 & - & - & + & $63.52 \%$ \\
\hline \multirow[t]{3}{*}{ MRS-E } & MRSE-1 & - & & - & - & + & - & - & + & - & $74.11 \%$ \\
\hline & MRSE-2 & - & 1.22 & - & - & - & - & - & - & - & $17.64 \%$ \\
\hline & MRSE-3 & 3.22 & - & 1.75 & + & - & - & + & + & + & $78.82 \%$ \\
\hline \multirow[t]{6}{*}{ MRS-S } & MRSS-1 & - & - & - & - & - & - & - & - & - & $64.70 \%$ \\
\hline & MRSS-2 & 1.44 & - & 2.99 & - & - & - & + & + & + & $78.82 \%$ \\
\hline & MRSS-3 & - & - & - & - & + & - & + & - & - & $76.47 \%$ \\
\hline & MRSS-4 & - & - & - & + & - & - & & - & - & $09.41 \%$ \\
\hline & MRSS-5 & 2.22 & - & 2.53 & + & - & 9.8 & + & - & + & $40.00 \%$ \\
\hline & MRSS-6 & - & - & - & - & - & - & - & - & - & $11.76 \%$ \\
\hline \multirow[t]{3}{*}{ CFA } & CFA-1 & - & - & - & - & - & - & + & + & + & $63.52 \%$ \\
\hline & CFA-2 & - & - & 4.12 & - & - & - & + & + & + & $35.29 \%$ \\
\hline & CFA-3 & - & - & - & - & - & - & - & + & + & $64.70 \%$ \\
\hline
\end{tabular}

$+=$ Positive, $-=$ Negative test

$*$ Zone of solubilization measured by considering formula zone diameter/colony diameter 
Fig.1 Phylogenetic tree of Myroids profundi (OF-4)

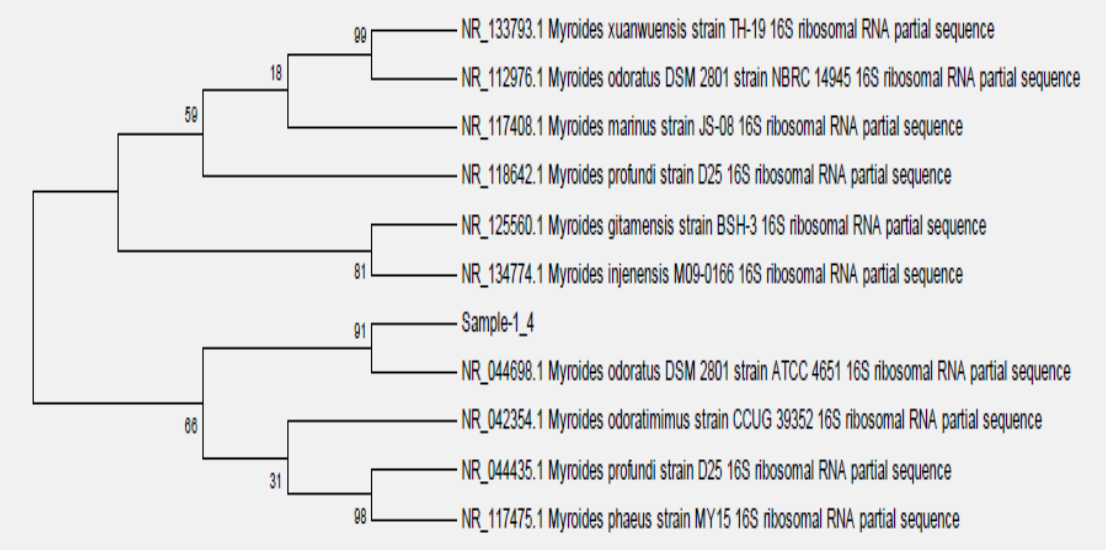

Fig.2 Phylogenetic tree of Proteus mirabilis (SWM-4)

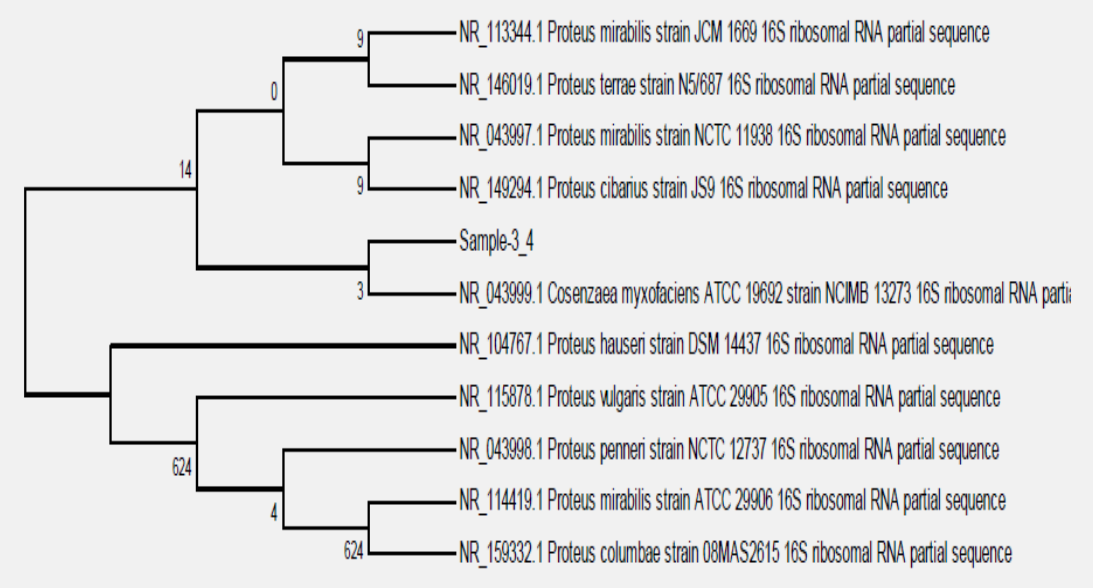

Surprisingly, all the isolated PGPR (100\%) showed antagonistic potential against Sclerotium rolfsii under lab conditions, PGI in the range of $7.05 \%$ to $80.00 \%$.

Kumar et al., (2012) studied different PGPR isolates for different plant growth promotion (PGP) activities as in vitro study. A total of thirty bacteria were isolated and screened for different plant growth promotion activities. Experimental data indicated that twelve bacterial isolates were positive for phosphate solubilization; IAA production was shown by almost all the bacterial isolates. Three isolates were positive for ammonia production, ACC deaminase activity was shown by nine isolates. Two isolates were positive for $\mathrm{HCN}$ production and all the isolates were found to be catalase positive, seven isolates were showing maximum plant growth promotion activities. These isolates were identified as Acinetobacter sp., Bacillus sp. and Pseudomonas sp.

Rani et al., (2011) studied on screening of rhizobacteria containing plant growth promoting (PGPR) traits in rhizosphere soils and their role in enhancing growth of pigeon 
pea. Sixty five (65) isolates were identified and characterized for their morphological, cultural, staining and biochemical characteristics, of which 35 was selected for the screening of PGPR isolates. Sixteen isolates were successfully characterized for the PGPR traits. Among the sixteen isolates, seven were found to be high IAA producing. Six were found to be efficient phosphate solubilizers, five isolates were found to be good antagonistic towards pathogen soil fungi and eight isolates were found to be better in enzyme productions, and thus, may enhance the mineralization efficiency of soils.

Many of the isolates were showing multiple PGP traits and found more potent in in vitro conditions. Out of all isolates, two isolates were most potent in terms of individual reactions and also showing multiple traits. Surprisingly, OF-4 was showing highest phosphate solubilization and positive for all the plant growth promotion parameters tested under in vitro conditions, except nitrogen fixation. Isolate SWM-4 was also good phosphate solubilizer as well as showing all the activities, except ACC deaminase, nitrogen fixation and starch hydrolysis.

\section{Biochemical and Molecular identification}

Two most potent PGPR isolates were identified 16'S r-RNA sequencing methods. Data revealed that OF-4 was identified as Myroids profundi and SWM-4 (PGPR-2) was identified as Proteus mirabilis (Figure 1 and 2).

In conclusion, plant needs micro and macro nutrients for growth and reproduction, absorbed in the form of solution from the surrounding environment. Additionally, plant has to face many biotic and abiotic stresses, resulting into compromising the productivity. In the conventional agriculture, use of agrochemicals are increasing to cope with devastating effect of different stresses and to increase productivity. However, prolonged use of synthetic agrochemcials is not only costly but also causes plant, soil and human health related issues. Use of PGPR in the ecofriendly and sustainable agriculture may be the ideal solution to cope up with harmful effect of synthetic chemicals.

\section{References}

Beneduzi, A., Ambrosini, A. and Passaglia, L.M. (2012). Plant growth-promoting rhizobacteria (PGPR): Their potential as antagonists and biocontrol agents. Genet Mol Biol. 35(4): 1044-1051.

Calvo, P., Nelson, L.M. and Kloepper, J.W. (2014). Agricultural uses of plant biostimulants. Plant Soil. 383: 3-41.

Chakraborty, U., Roy, S., Chakraborty, A.P., Dey, P. and Chakraborty, B. (2011). Plant growth promotion and amelioration of salinity stress in crop plants by a salt-tolerant bacterium. Recent Res. Sci. Technol., 3(11): 6170.

Dobbelaere, S., Croonenberghs, A., Thys, A., VandeBroek, A. and Vanderleyden, J. (1999). Photostimulatory effects of Azospirillum brasilense wild type and mutant strain altered in IAA production on wheat. Plant. Soil., 212: 155-164.

Glick, B.R. (2012). Plant Growth-Promoting Bacteria: Mechanisms and Applications. Hindawi Publishing Corporation, Scientifica; Waterloo, Canada.

Glick, B.R., 1995. The enhancement of plant growth by free-living bacteria. Can.J. Microbiol., 41: 109117.

Glick, B.R., Jacobson, C.B., Schwarse, M.M.K. and Pasternak, J.J. (1994). 1Aminocyclopropane-1-carboxylic acid deaminase mutants of the plant growth promoting rhizobacterium 
Pseudomonas putida GR 12-2 do not stimulate canola root elongation. Can. J. Microbiol. 40: 911-915.

Jeyalakshmi, S. and Radha, R. (2017). A review on diagnosis of nutrient deficiency symptoms in plant leaf image using digital image processing. ICTACT journal on image and video processing. 7(4): 1515-1524.

Kloepper, J.W. and Schroth, M.N. (1978). Plant growth promoting rhizobacteria on radishes. Proc. 4th Int. Conf. Plant path. Bact., Angers, P. 879-882.

Kumar, A., Kumar, A., Devi, S., Patil, S., Payal, C. and Negi, S. (2012). Isolation, screening and characterization of bacteria from rhizospheric soils for different plant growth promotion (PGP) activities: an in vitro study. Rec. Res Sci. Technol., 4(1).

Lynch, J.M. (1985). Origin, nature and biological activity of aliphatic substances and growth hormones found in soil. In: Vaughan, D., Malcom, R. E. (Eds). Soil Organic Matter and Biological Activity. Martinus Nijhoff /Dr. W. Junk Publishers. Dordrecht, Boston, Lancaster. pp. 151-174.

Morgan, J. B. and Connolly, E. L. (2013) Plant-Soil Interactions: Nutrient Uptake. Nature Education Knowledge 4(8): 2

Nihorimbere, V., Ongena, M, Smargiassi, M. and Thonart, P. (2011). Beneficial effect of the rhizosphere microbial community for plant growth and health. Biotechnol. Agron. Soc.
Environ., 15(2): 327-337.

Pikovskaya, R.I. (1948). Mobilization of phosphorus in soil connection with the vital activity of some microbial species. Microbiologiya. 17: 362-370.

Rajnish, P. S. and Prabhat, N. J. (2015). Plant growth promoting potential of ACC deaminase rhizospheric bacteria isolated from Aerva javanica: A Plant adapted to saline environments. Intl. J. Curr. Microbiol. App. Sci. 4(7): 142152.

Rani, U., Arundhathi, M. and Gopal, R. (2011). Bacillus cereus and Enterobacter cancerogenus screened for their efficient plant growth promoting traits rhizobacteria (PGPR) and antagonistic traits among sixteen bacterial isolates from rhizospheric soils of Pigeon Pea. Afr. J. Microbiol. Res. 5: 2090-2094.

Venkatakrishnan, S.S., Sudalayandy, R.S. and Savariappan, A.R. (2003). Assessing in vitro solubilization potential of different zinc solubilizing bacterial (ZSB) strains. Braz. J. Microbiol., 34: 121-125

Vincent, J.M. (1947). The esters of 4hydroxybenzoic acid and related compounds. Part I. Methods for the study of their fungistatic properties. $J$. Soc. Chem. Ind., 66: 149-155.

Yu, Y., Chu, X., Pang, G., Xiang, Y. and Fang, H. (2009). Effects of repeated applications of fungicide carbendazim on its persistence and microbial community in soil. J. Environ. Sci., 21: 179-185.

\section{How to cite this article:}

Hiral Bhanderi and Khunt, M.D. 2019. Screening of Multi-trait PGPR from Rhizosphere of Sugarcane (Saccharum officinarum L.). Int.J.Curr.Microbiol.App.Sci. 8(06): 617-623. doi: https://doi.org/10.20546/ijcmas.2019.806.071 